\title{
O instituto privado da Teoria da Imprevisão e a sua aplicabilidade no contrato administrativo
}

\author{
Isabela Pinto de Souza Mello \\ Pós-graduando no curso de Direito Administrativo \\ da rede de ensino LFG/Anhanguera.
}

\begin{abstract}
RESUMO
O tema desenvolvido tem por escopo analisar, brevemente, o disciplinamento dos contratos administrativos, especialmente, a relação de predominância do interesse público sobre a aplicabilidade de alguns institutos privados correlatos à teoria geral dos contratos. Como hipótese suscitada para alcance da resposta a questão, sugere-se: a teoria da imprevisão tem se mostrado como o meio mais adequado para mitigar a obrigatoriedade contratual. A problemática vislumbrada é expressa na correlação entre o desenvolvimento de negócios jurídicos celebrados pelo Estado-Administração, que não podem ser desnaturalizados ao ponto de perderem a sua natureza própria e não serem firmados com liberdade irrestrita, incompatível com a figura do Estado. O objetivo geral é analisar ainda que sucintamente a necessidade da Administração celebrar pactos bilaterais e a correlação das características próprias dos contratos administrativos e a aplicabilidade de normas do Direito Civil que disciplinam a teoria geral dos contratos, seja de forma predominante ou subsidiária. Quanto à metodologia empregada, trata-se de uma pesquisa básica com abordagem qualitativa, objetivo exploratório, delineamento bibliográfico e documental. A tipologia metodológica utilizada repousou no método dedutivo.
\end{abstract}

Palavras-chave: Aplicabilidade; Teoria; Imprevisão.

\begin{abstract}
The purpose of this study is to analyze briefly the discipline of administrative contracts, especially the relationship between the public interest and the applicability of some private institutes related to the general theory of contracts. As a hypothesis raised to reach the answer to the question, it is suggested: the theory of the forecast has been shown as the most appropriate means to mitigate the contractual obligation. The problematic envisaged is expressed in the correlation between the development of legal business concluded by the State Administration, which can not be distorted to the point of losing their proper nature and not be signed with unrestricted freedom, incompatible with the State. The general objective is to analyze briefly the need for the Administration to conclude bilateral pacts and the correlation of the characteristics of administrative contracts and the applicability of Civil Law norms that govern the general theory of contracts, be it predominantly or subsidiary. As for the methodology used, this is a basic research with a qualitative approach, exploratory objective, bibliographic and documentary delineation. The methodological typology used was based on the deductive method.
\end{abstract}

Keywords: Applicability; Theory; unpredictability 


\section{INTRODUÇÃO}

O presente trabalho tem o objetivo geral de contribuir para o estudo dos indicativos consequenciais e circunstanciais, ainda que de maneira sucinta, advindos da atual temática inerente a necessidade da Administração celebrar pactos bilaterais com terceiros ou como outros entes da Administração objetivando a consecuções de interesses públicos. Apesar de suas características próprias, os contratos administrativos possuem regência de normas do Direito Civil que disciplinam a teoria geral dos contratos, seja de forma predominante ou subsidiária.

Quanto à metodologia empregada, propõe-se uma pesquisa básica com abordagem qualitativa, objetivo exploratório, delineamento doutrinário.

Para a epistemologia, o instituto da Teoria da Imprevisão está automaticamente inserido dentro da órbita do Direito Administrativo e, por via consequente do contrato administrativo, porém, o presente estudo destina-se, num primeiro ensaio, abordar, brevemente, o histórico de tal teoria e predominância da natureza privada.

Com o advento da concepção e fortalecimento da figura do Estado, este passou a ser posto como um ente capaz de firmar pactos bilaterais, ou seja, capaz de ser parte em relações obrigacionais comumente desenvolvidas no âmbito do Direito privado. Não obstante, verificou-se uma problemática correspondente à correlação entre o desenvolvimento de negócios jurídicos celebrados pelo EstadoAdministração, que não podem ser desnaturalizados ao ponto de perderem a sua natureza própria e nem serem firmados com liberdade irrestrita, incompatível com a figura do Estado.

Nessa senda o ordenamento jurídico brasileiro, visando uma harmonização, sedimentou o firmamento de dois regimes diversos de contratação para a Administração. A saber: a aplicação dos princípios gerais do contrato e das disposições de Direito Privado, de forma predominante para um, e, subsidiariamente para o outro.

Por esse ínterim, o artigo em epígrafe objetiva responder a esse questionamento, bem como elucidar e explicitar pontos relevantes acerca dos contratos administrativos e relação/aplicabilidade da teoria da imprevisão, cujas 
facetas são utilizadas como objeto delimitador do presente trabalho, apurando, brevemente, seus aspectos jurídicos que o envolvem.

Analisar-se-á, sucintamente, alguns elementos da teoria geral dos contratos administrativos, bem como a dicotomia entre o princípio do pacta sunt servanda ou princípio da obrigatoriedade dos contratos e alterações nas bases de fato da relação contratual, especialmente quanto à execução/inexecução. Nesse quadro a teoria da imprevisão tem se mostrado como o meio mais adequado para mitigar a força implacável da obrigatoriedade contratual.

Num segundo momento, propor-se-á estudos específicos voltados para o sobrevoo da inexecução contratual, bem como a necessidade de rompimento ou exaurimento do contrato administrativo.

Por fim, desenvolver-se-á a temática da inexecução do contrato administrativo, utilizando a teoria da imprevisão como importante fator, utilizando o método dedutivo para a comprovação da problemática que envolve a sua aplicação nos contratos públicos.

\section{RÁPIDA ABORDAGEM DA TEORIA GERAL DO CONTRATO ADMINISTRATIVO}

Neste início de capítulo, Carvalho Filho (2018, p.245) conceitua, de forma simples, o contrato administrativo como "o ajuste firmado entre a Administração Pública e um particular, regulado basicamente pelo direito público, e tendo por objeto uma atividade que, de alguma forma, traduza interesse público."

Todavia cabe esclarecer e registrar que, tendo em vista às várias especificações e temáticas que envolvem os contratos administrativos, este capítulo, delimitará como corte de tema uma abordagem breve sobre conceito do contrato administrativo, cláusulas essenciais e a correlação e algumas distinções com contrato privado.

Não é por demais mencionar que o contrato administrativo é regido pela Lei Federal no 8.666/93, dispositivo de norma geral abstrata, e de competência da União, cujos objetos de abordagem jurídica genérica sedimentam a licitação pública e o contrato administrativo/público. 
Desta forma, subordinam-se ao regime do contrato administrativo imposto pelo artigo 1ํㅡㄹ parágrafo único, Lei ํㅜ 8.666/93, além dos órgãos da Administração direta, os fundos especiais, as autarquias, as fundações públicas, as empresas públicas, as sociedades de economia mista e demais entidades controladas, direta ou indiretamente, pela União, pelos Estados, Distrito Federal e Municípios.

Nesse caminhar, o conceito de contrato administrativo pode ser abstraído da própria Lei nº 8.666 de 1993, em seu art. 2ª , parágrafo único:

"Art.2ำ As obras, serviços, inclusive de publicidades, compras, alienações, concessões, permissões e locações da Administração Pública, quando contratadas com terceiros, serão necessariamente precedidas de licitação, ressalvadas as hipóteses previstas nesta Lei. Parágrafo único. Para os fins desta Lei, considera-se contrato todo e qualquer ajuste entre órgãos ou entidades da Administração Pública e particulares, em que haja um acordo de vontades para a formação de vínculo e a estipulação de obrigações recíprocas, seja qual for a denominação utilizada."

Em linhas conceituais genéricas e simplórias, o Contrato Administrativo é todo e qualquer pacto entre órgãos ou entidades da Administração Pública e particulares, em que há, por obviedade, um acordo de vontade para a formação de vínculo e a estipulação de obrigações recíprocas. Há de se observar com base no Princípio da Supremacia do Interesse público, o contrato administrativo se destaca por sua forma peculiar no que diz respeito à sua celebração, onde a Administração impõe previamente as regras, a vontade do particular/administrado, visando sempre o interesse público.

Mello (2009, p.614) define contrato administrativo como:

(...) um tipo de avença travada entre a Administração e terceiros na qual, por força de lei, de cláusulas pactuadas ou do tipo de objeto, a permanência do vínculo e as condições preestabelecidas assujeitamse a cambiáveis imposições de interesse público, ressalvados os interesses patrimoniais do contratante privado (...). 
$\mathrm{Na}$ acepção de Alexandrino e Paulo (2011) o contrato administrativo enquadra-se na categoria dos denominados contratos de adesão, vez que, uma das partes propõe as cláusulas e a outra não pode propor alterações, supressões ou acréscimos a essas.

Via de regra os contratos devem necessariamente ser escritos, sendo considerados inválidos os contratos verbais, com exceção das compras de pequeno valor e pronto pagamento, segundo as balizas do art. 60, parágrafo único, da lei no 8.666/1993. Relembra-se que um extrato do contrato deve ser publicado pela imprensa oficial, o que vem a atender à exigência de publicidade, elemento essencial para o controle da Administração, por via da própria sociedade.

No que atine as cláusulas essenciais do contrato administrativo há obrigatoriedade de expressa transcrição de cláusulas elencadas no art. 55 do Diploma pertinente. Dentre outras, a que defina o objeto e suas características, que indique o regime de execução, bem como o preço e as condições de pagamento, que desmarque os prazos, que aponte os recursos, que fixe a responsabilidade das partes e que estabeleça as condições de importação, etc.

Desta forma, Carvalho Filho (2018, p.247), preleciona que

(...)constituem cláusulas essenciais dos contratos administrativos aquelas indispensáveis à validade do negócio jurídico. As cláusulas que não têm esse condão e que variam em conformidade com a natureza do contrato são consideradas acidentais (...).

\subsection{CONSIDERAÇÕES SOBRE CONTRATO PRIVADO, CORRELAÇÃO E DICOTOMIA COM O CONTRATO PÚBLICO.}

É pertinente citar que a Administração Pública reconheceu prima facie a utilidade do instrumento do contrato para a satisfação de seus objetivos. No entanto, a interveniência no campo dos contratos gerou incômodos de ordem epistemológica na doutrina, em razão da aparente incompatibilidade entre os princípios que regem o Direito Civil e o Direito Público, especialmente os exteriorizados pela teoria dos contratos. 
Notoriamente, o contrato administrativo envolve características singulares do contrato privado (consensual, formal, oneroso, comutativo e "intuito persane") e uma característica própria do Direito Administrativo que é a prévia licitação e as presença das cláusulas exorbitantes, ou seja, nos contratos administrativos há incidência de normas de Direito Público, mas o princípio da teoria geral dos contratos e as normas de Direito Privado são aplicadas supletivamente.

Outra correlação reside na obrigatoriedade em que o contratado é responsável pelos encargos trabalhistas, previdenciários, fiscais e comerciais resultantes da execução do contrato, sendo a Administração Pública solidária com o contratado com relação aos encargos previdenciários não pagos durante a execução do contrato.

Semelhantemente, o contrato administrativo, assim como o contrato privado, promover-se-á por duas declarações de vontade concordantes carentes de recepção: uma solicitação de conclusão de contrato (proposta), e sua aceitação.

Já em relação ao equilíbrio financeiro, nos contratos privados, uma vez desconstituída a equivalência de equilíbrio durante o contrato, este somente poderá ser novamente implementada por acordo entre as partes. Nos contratos administrativos, por outro lado, deve a Administração pública, sempre que possível buscar a equivalência material das prestações.

Visualiza-se em finalização, uma diferença relevantes nas relações contratuais: na órbita do direito privado, as partes se situam no mesmo plano jurídico e impera o princípio do pacta sunt servanda, o qual as obrigações do contrato devem ser cumprida e respeitada integralmente, devendo ser sempre mantidas, no direito público impera a prevalência da máxima da supremacia da Poder Público sobre o particular.

Sabe-se que nos contratos administrativos não há aplicabilidade da "exceção do contrato não cumprido" (exceptio non adimpleti conttractus), usualmente invocada nos ajustes de Direito Privado, em razão do impeditivo imposto pelo princípio da continuidade do serviço público, que veda a paralisação da execução do contrato mesmo diante da omissão ou atraso do Poder Público no cumprimento das prestações a seu cargo. 
Em outras palavras, a cláusula exceptio non adimpleti conttractus presente no Direito Privado aduz que uma parte pode deixar de satisfazer sua obrigação no contrato pelo fundamento do não cumprimento da obrigação por parte do outro. Isso não ocorre no contrato administrativo, pelo fato que imperar os princípios da supremacia do interesse público e da continuidade do serviço público.

Assim, finalize-se a primeira abordagem com a premissa de que as diretrizes dos contratos públicos ora se entrelaçam com as do contrato privado, ora chocam-se com as diretrizes de princípios, naturalmente postas a esses dois ramos do Direito.

\section{CONTRATOS ADMINISTRATIVOS - POSSILIDADE DE ALTERAÇÃO - TEORIA DA IMPREVISÃO}

Traga-se a baila, neste capítulo, antes de adentrar na aplicabilidade propriamente dita da Teoria da Imprevisão, a possibilidade de alteração e a abordagem ligeira sobre áleas, especialmente, econômica administrativa.

Inicialmente cita-se que o art. 65 da Lei no 8.666/1993 estabelece a regra relacionada às alterações contratuais. Unilateralmente, pertinente relembrar, a Administração só poderá fazê-lo quando houver modificação do projeto ou das especificações e quando for necessária a modificação do valor contratual em decorrência de acréscimos ou supressões, dentro dos limites legais.

A par disso, a redação do art. 65, II, "d" e dos seus $\S \S 5^{\circ}$ e 6ำ reflete uma salutar preocupação do legislador em proteger o particular que celebra pactos com o Poder Público no tocante à superveniência de fatos imprevisíveis que tornem inviável a execução do objeto contratual.

Dessa maneira, qualquer circunstância nova que venha a afetar o corriqueiro equilíbrio financeiro incialmente avençado pode e deve ensejar a revisão do contrato. Fatos imprevisíveis, ou previsíveis, porém de consequências incomensuráveis, que retardem ou causem impedimentos à execução contratual, ou, ainda, em caso de força maior, caso fortuito de fato de príncipe, configurando-se álea econômica extraordinária e extracontratual.

De todo modo, pode-se afirmar que o equilíbrio do contrato administrativo é essencialmente dinâmico, trazendo à baila três tipos de riscos ou, áleas, que o 
particular encara quando contrata com a administração: álea ordinária ou empresarial, álea administrativa e álea econômica.

Todavia, para uma melhor concatenação do objeto de estudo, conceitua-se álea econômica, que dá lugar à aplicação da Teoria da Imprevisão, fundada na antiga cláusula rebus sic stantibus, é todo acontecimento que pode ser provocado por fatores estruturais da economia ou fatores externos ao contrato, estranho à vontade das partes, excepcionais e extraordinários, que causa um desequilíbrio econômico e financeiro, tornando a execução do contrato excessivamente onerosa para qualquer dos contratantes.

Impede destacar que a distinção entre álea ordinária e extraordinária se relaciona não com a mera possibilidade de ocorrência dos eventos, mas sim com a probabilidade de sua ocorrência. Se assim não fosse, todo o evento possível seria, em tese, previsível, integrado a álea extraordinária somente eventos impossíveis, que, por definição, nunca viria a ocorrer.

Segundo Di Pietro (2018, p.596) há três tipos de áleas ou riscos que particular enfrenta quando contrata com a Administração, nestes verbetes:

1.álea ordinária ou empresarial, que está presente em qualquer tipo de negócio; é um risco que todo empresário corre, como resultado da própria flutuação do mercado; sendo previsível, por ele responde o particular. Há quem entenda que mesmo nesses casos a Administração responde, tendo em vista que nos contratos administrativos os riscos assumem maior relevância por causa do porte dos empreendimentos, o que torna mais difícil a adequada previsão dos gastos; não nos parece aceitável essa tese, pois, se os riscos não eram previsíveis, a álea deixa de ser ordinária;

2.álea administrativa, que abrange três modalidades:

a)uma decorrente do poder de alteração unilateral do contrato administrativo, para atendimento do interesse público; por ela responde a Administração, incumbindo-lhe a obrigação de restabelecer o equilíbrio voluntariamente rompido;

b)a outra corresponde ao chamado fato do príncipe, que seria um ato de autoridade, não diretamente relacionado com o contrato, mas 
que repercute indiretamente sobre ele; nesse caso, a Administração também responde pelo restabelecimento do equilíbrio rompido;

c) a terceira constitui o fato da Administração, entendido como "toda conduta ou comportamento desta que torne impossível, para o cocontratante particular, a execução do contrato" (Escola, 1977, v. l:434); ou, de forma mais completa, é "toda ação ou omissão do Poder Público que, incidindo direta e especificamente sobre o contrato, retarda, agrava ou impede a sua execução" (Hely Lopes Meirelles, 2003, p.233);

3.álea econômica, que corresponde a circunstâncias externas ao contrato, estranhas à vontade das partes, imprevisíveis, excepcionais, inevitáveis, que causam desequilíbrio muito grande no contrato, dando lugar à aplicação da teoria da imprevisão; a Administração Pública, em regra, responde pela recomposição do equilíbrio econômico-financeiro.

Em apertada síntese, a álea ordinária dos contratos é aquela que é comum a toda atividade empresarial. Áleas extraordinárias subdividem-se em áleas administrativas - alteração unilateral do contrato, fato do príncipe e fato da Administração, que, porquanto tenham sido ocasionadas pela atuação da Administração Pública - e econômicas -, na qual se encontra a Teoria da Imprevisão.

\subsection{CONTRATOS ADMINISTRATIVOS VERSUS INSTITUTO PRIVADO DA TEORIA DA IMPREVISÃO}

O art. 54 da Lei no 8.666/1993 prevê que "os contratos administrativos de que trata esta Lei regulam-se pelas suas cláusulas e pelos preceitos de direito público, aplicando-se Ihes, supletivamente, os princípios da teoria geral dos contratos e as disposições do direito privado."

A Teoria da Imprevisão visa autorizar a revisão contratual com o objetivo de restabelecer o equilíbrio contratual, caso ocorra eventos imprevisíveis alheios à vontade das partes. Tal Teoria encontra respaldo constitucional e na Lei 8.666/1993, 
sendo aplicada aos contratos administrativos, uma vez que se baseia nos princípios da igualdade, da continuidade dos serviços públicos e boa-fé.

Em contextualização da problemática deste trabalho, menciona-se que a teoria em pauta este umbilicalmente atrelada ao princípio da obrigatoriedade dos contratos, mas se revela como uma mitigação a este. Infere-se que a teoria da imprevisão é um dos principais avanços trazidos pela visão mais humanitária do Direito.

O estado de imprevisão são fenômenos da instabilidade econômica e social, tais como guerras, crises econômicas, não podendo mensurar o impacto dos seus efeitos e suas conseqüências desastrosas. Por essa razão, o objetivo dessa teoria é restabelecer o equilíbrio entre o encargo e a retribuição, fazendo com que o contrato seja mais justo para ambas as partes.

De todo modo, a Teoria da Imprevisão pode acarretar as seguintes possibilidades, tais como: se a parte prejudicada não conseguir arcar com as obrigações contratuais devido ao fato imprevisível, o contrato rescinde sem culpa das partes, mas caso seja possível o cumprimento das obrigações contratuais, mesmo com ônus para a parte, esta poderá pedir a revisão do contrato para restabelecer a situação econômica do contrato.

Em conclusão derradeira e contextualizando o apresentado neste capítulo, de maneira geral, é possível inferir que para a configuração e aplicação da Teoria da Imprevisão no âmbito dos contratos administrativos, o fato superveniente deve ser imprevisível ou previsível, mas de consequências incalculáveis; não decorrente de culpa ou dolo do particular contratante ou da Administração Pública; e desestabilizador da equação econômico-financeira da avença que, por sua vez, deve ser de longa duração ou, ao menos, prever obrigações a serem cumpridas em momento posterior.

\section{CONCLUSÃO}

A conclusão em pauta define-se pela temática lastreada na problemática central se o instituto da Teoria da Imprevisão está automaticamente inserida dentro da órbita do Direito Administrativo e, por via consequente do contrato administrativo. 
Destarte abordou-se brevemente, o histórico de tal teoria e predominância da natureza privada.

Analisou-se que na compreensão do instituto do contrato administrativo no âmbito da Lei 8.666/1993 a correlação entre o desenvolvimento de negócios jurídicos celebrados pelo Estado-Administração não podem ser desnaturalizados ao ponto de perderem a sua natureza própria e nem serem firmados com liberdade irrestrita, incompatível com a figura do Estado. Pode-se suscitar que essas proposições preencheram o objetivo geral.

Após abordagem das análises referenciais é possível concluir que o instituto de Direito Privado está regulado pelos princípios da autonomia da vontade, da obrigatoriedade dos contratos, da boa-fé e da função social do contrato.

Por outro lado, as atuações do Poder Público está instruída pelo princípio da supremacia do interesse público sobre o privado. Ao analisar a Lei 8.666/93, o que se vê é uma proteção contundente do Poder Público. Nos contratos administrativos a Administração se sobressai com uma série de prerrogativas que garantem a sua posição de supremacia sobre o particular. Tal identificação alcançou um dos objetivos específicos do trabalho.

Nessa senda ligeiramente conflituosa, o particular que celebra contrato com a Administração, fica praticamente com reações restritas perante a alguma providência que tiver que ser tomada no tocante ao contrato, tendo em vista que, as regras já vêm previamente estabelecidas, não tendo o contratado, via de regra, o direito de expressar sua vontade, a não ser que procure a tutela do Poder Judiciário, único mio de sanar estas entre outras pendências.

Isto é, acontecimentos imprevisíveis que gerarem excessivo ônus para o particular, sendo impossível o cumprimento do contrato, permite que a parte recorra às vias administrativas ou judiciais, pleiteando a rescisão contratual, mas sem interromper a execução do contrato.

Verificou-se que a Teoria da Imprevisão tem assento constitucional e se encontra insculpida na Lei n. 8.666/1993, mas, ainda que assim o fosse, essa seria aplicável aos contratos administrativos, eis que fundada em princípios da igualdade, boa-fé e continuidade dos serviços públicos. 
É possível inferir que para a configuração e aplicação da Teoria da Imprevisão no âmbito dos contratos administrativos, o fato superveniente deve ser imprevisível ou previsível, mas de consequências incalculáveis; não decorrente de culpa ou dolo do particular contratante ou da Administração Pública; e desestabilizador da equação econômico-financeira da avença que, por sua vez, deve ser de longa duração ou, ao menos, prever obrigações a serem cumpridas em momento posterior. Igualmente após a apresentação deste cenário, alcançou-se objetivo específico derradeiro.

Em contextualização, carreou-se a premissa que as diretrizes dos contratos públicos, ora se entrelaçam, com as do contrato privado, ora chocam-se com as diretrizes de princípios, naturalmente postas a esses dois ramos do Direito. Todavia é evidente a relação da predominância do interesse público sobre a aplicabilidade de alguns institutos privados.

Por essa razão, a Teoria da Imprevisão nos contratos administrativos deve ser aplicada excepcionalmente, uma vez que não pode Administração arcar integralmente com os prejuízos resultantes dos eventos imprevisíveis. Todavia, a Administração pode dividir os encargos com a parte prejudicada para 0 restabelecimento do equilíbrio econômico-financeiro, visando a continuidade da execução do contrato.

Desta forma, não cabe a Administração responder integralmente por fatos que ela não deu causa, deve-se repartir os prejuízos com o particular, pois ambos assumiram o risco de eventuais imprevistos, retardadores ou impeditivos da execução do ajustado, quando se comprometeram a adimplir as obrigações contratuais estabelecidas inicialmente no contrato.

\section{REFERÊNCIAS}

BEHRING, E. R.; BOSCHETTI, I. Política social: fundamentos e história. São Paulo: Cortez, 2007.

BASTOS, C. Curso de direito administrativo. São Paulo: Saraiva, 1994.

CARVALHO FILHO, J. Manual de direito administrativo. Rio de Janeiro: Editora Atlas, 2018. 
CRETELLA JÚNIOR, J. Curso de direito administrativo. Rio de Janeiro: Forense, 1997.

DI PIETRO, M. S. Z., Direito administrativo. São Paulo: Atlas, 2018.

GILISSEN, H. Direito administrativo geral. Barueri: Manole, 2006.

MAIA, P. C. Da cláusula "rebus sic stantibus”. São Paulo: Editora Saraiva, 1959.

MEIRELLES, H. L. Direito administrativo brasileiro. São Paulo: Malheiros, 1999.

MELLO, C. A. B. Curso de direito administrativo. São Paulo: Malheiros, 2009.

SANTOS, J. A. A. Contratos de concessão de serviços públicos: equilíbrio econômico-financeiro. Curitiba: Juruá, 2007.

TARTUCE, F. Manual de direito civil: volume único. Rio de Janeiro: Forense, 2014. 